\title{
Adherence, physical limitation and social participation in leprosy patients in a high-complexity hospital
}

Amanda Henriques Cavalheiro ( $\sim$ amanda.cavalheiro@usp.br )

Universidade de São Paulo

Marco Andrey Cipriano Frade

Universidade de São Paulo

Andrea Queiroz Ungari

Universidade de São Paulo

\section{Research Article}

Keywords: Educational tools, Leprosy, Medication Adherence, Pharmaceutical care

Posted Date: March 2nd, 2022

DOI: https://doi.org/10.21203/rs.3.rs-1251376/v1

License: (c) (i) This work is licensed under a Creative Commons Attribution 4.0 International License.

Read Full License 


\section{Abstract}

Background: Therapies and procedures to improve the quality of life of patients and adherence to treatment is a concern for the health systems and for health professionals. More studies related to preventive and therapeutic education, using educational technologies for health purposes are needed.

Objectives: To demonstrate the educational instruments developed by the researcher, as animated videos and posts, as well as the pharmacotherapeutic monitoring of pharmaceutical care, increase the adherence to the treatment of patients diagnosed with leprosy in a high-complexity hospital.

Methods: This is a longitudinal study, using quantitative and qualitative assessment tests to assess adherence to treatment and general knowledge about the disease and quality of life. From the data, educational materials were produced and tested on patients. Then, the impact of follow-up and instructional materials on treatment adherence was evaluated.

Results: Treatment adherence increases after the intervention of pharmaceutical care and health education, as per the Morisky-Green treatment test. The methodology was more effective in male patients with low education than in women, who already had high adherence. In addition, it was possible to identify that the Morisky-Green and Haynes-Sackett adhesion tests, used in the work, completely differed in their results, they occur to reflect the use of such tools in research in the area.

Conclusion: It is possible to increase patient treatment adherence through health education programs and pharmaceutical care.

\section{Introduction}

Leprosy is an infectious contagious disease, caused by Mycobacterium leprae and by Mycobacterium lepromatosis, more recently discovered ${ }^{1}$. The disease affects several individual's ability, for example, to walk, due to changes in the functionality of the Peripheral Nervous System (upper and lower nerves). Patients can develop severe sequelae, such as ciliary madarosis, or often the appearance of lesions requiring amputation of the affected area ${ }^{2}$.

Transmission occurs through intimate and prolonged contact between a person who is more likely to become ill (or genetically predisposed) with an untreated leprosy patient. Transmission occurs through the airways (air) ${ }^{3}$.

According to the WHO, in $2019,202,185$ new cases of the disease were reported in the world, with $93 \%$ located in the region of the Americas ${ }^{4}$. More than 27 thousand cases were reported in Brazil, $5.5 \%$ in children under 15 years of age ${ }^{5}$. Its incidence in Brazil is the second highest in the world, second only to India ${ }^{4,5}$. Furthermore, it is closely related to stigmas, especially when associated with deformities ${ }^{6}$.

The treatment of leprosy includes medication and self-care. Self-care is related to preventing the progression of the disease and disabilities, focusing on the region of the eyes, nose, feet and hands ${ }^{7}$. 
With the proper use of the drug, the disease can be cured and its transmission interrupted. Depending on the diagnosis, the treatment varies from 6 months for Paucibacillar (PB) and 12 months for Multibacillar $(\mathrm{MB})$, with a specific regimen of drugs ${ }^{6}$.

Overall, it is estimated that 40 to $60 \%$ of patients do not use prescribed medications, making adherence to treatment one of the biggest problems faced in medical practice ${ }^{8}$.

Patients with chronic diseases have difficulties in adhering to treatments and, as a consequence, medical and psychosocial complications of the disease reduce the quality of life of patients, in addition to wasting health resources ${ }^{9}$.

Taking into account all factors associated with this disease, the aim of this study was to to evaluate the impact of pharmaceutical interventions on adherence to drug treatment in leprosy patients followed up at the Dermatology Outpatient Clinic of the University of São Paulo at Ribeirão Preto Medical School Hospital das Clínicas.

\section{Methods}

\section{Study design}

A prospective intervention study was carried out, where educational and follow-up activities were developed, with qualitative analysis of the patients' general knowledge about leprosy and quantitative analysis, with adherence tests.

\section{Study location and period}

The study was carried out at the Hansen's Disease Outpatient Clinic of the Hospital das Clínicas, USP's Ribeirão Preto Medical School (HCFMRP-USP), where patients with an indication for treatment for leprosy were invited to participate in the study that took place between October 2020 and June 2021.

\section{Study population}

Patients who were already in treatment and/or who would start their treatment during the study were considered eligible to participate in the study.

It is important to note that the patients at the Dermatology Outpatient Clinic of HCFMRP-USP are, almost entirely, relapsed patients with the disease, that is, they had already been discharged at some other time, but there was a relapse, with drug resistance and need for treatments substitutes.

The application of the questionnaires used in the research was carried out through a face-to-face interview between the researcher and the participant, after signing the Informed Consent Form (FICF).

In calculating the sample, the McNemar test methodology for paired proportions was considered, adopting $80 \%$ as the test power and a bilateral significance level of $5 \%$. Based on these data, the 
estimated sample size for conducting this research was 38 individuals ${ }^{10}$.

\section{Inclusion and exclusion criteria}

The study inclusion criteria were: aged 18 years or over; both sexes; main diagnosis of the defined disease to be studied; withdraw of medication at the HCFMRP-USP Ambulatory Pharmacy; agreement with the Informed Consent Form (FICF).

Exclusion criteria were patients who were on the last dose of treatment.

\section{Patient demographic and social characteristics}

Demographic data were described.

\section{Aspects related to the patient's pharmacotherapy}

To assess adherence to treatment, the following tests were performed: Morisky-Green Test (MGT) normal and extended and Haynes-Sackett test (HST).

The MGT consists of four questions, which aim to assess the patient's behavior in relation to the usual use of the medication ${ }^{11}$. The questions are:

1) Do you sometimes have problems remembering to take your medication?

2) Do you sometimes neglect to take your medication?

3) When you are feeling better, do you sometimes stop taking your medication?

4) Sometimes, if you feel worse while taking the medication, do you stop taking it?

The patient is classified in the high-adherence group, when the answers to all questions are negative. Each negative response is assigned a value of $25 \%$ for adherence, totaling $100 \%$ adherence to treatment. For this study, only patients with a high degree of adherence were considered. In other words, if the answer to any question was affirmative, the patient was included as non-adherent to the treatment.

In the expanded test, it is also evaluated whether knowledge about the drug was transmitted by the health professional and the patient's motivation in the treatment. The questions are:

1) Were you informed about the importance of taking this medication?

2) Do you forget to replace your medications when they run out?

The MGT was repeated after the pharmaceutical intervention for 1 to 6 months, as described above.

In HST, the patient is asked a single question if he had any difficulty taking his medications in the last 30 days ${ }^{12}$ : "Many people have some kind of problem taking their medications. In the last 30 days, have you had difficulties taking your medication?" 
If so, the patient is considered as non-adherent. If not, the patient is classified as compliant. This test was repeated after the pharmaceutical intervention for 1 to 6 months.

\section{SALSA Scale}

The SALSA Scale stands for Screening of Activity Limitation and Safety Awareness and aims to assess the extent of activity limitation and the risk of increasing impairments during activities, developed for analysis of physical limitation in patients with leprosy and/or diabetes ${ }^{13}$.

The scale covers eyes, hands (skill and work), feet (mobility) and self-care. The score ranges from 10 to 80 and, the lower the score, the less difficulty with activities of daily living and higher values are indicative of increasing levels of activity limitation: from 10-24 (no limitation); 25-39 (slight limitation); 40-49 (moderate limitation); 50-59 (severe limitation); 60-80 (very severe limitation).

In addition to the general questions, the risk awareness score must also be calculated. The result will be a score between 0 and 11. Higher scores indicate an increasing awareness of the risks involved in certain activities, but also indicate that there is activity limitation due to this.

\section{Participation Scale}

The Participation Scale uses the concept of PAR, where the respondent thinks of someone similar to him in all aspects, except for the disease. The respondent is instructed to think about this PAR in order to eliminate differences in participation resulting from gender, social class, etc. This scale assesses the degree of social impairment that the disease causes in the patient's life ${ }^{14}$.

The scale score is a classification of degrees of participation restriction: 0-12 (no significant restriction); 13-22 (slight restriction); 23-32 (moderate restriction); 33-52 (severe restriction); 53-90 (extreme restriction).

After the follow-up of the patients, which lasted from 1 to 6 months, the Participation Scale was repeated, in order to assess whether the intervention performed was able to change the social aspects perceived by the patient.

\section{Assessment of patients' general knowledge}

In order to assess the patients' knowledge about the disease and their beliefs about the subject, a questionnaire was carried out to help guide the teaching activities. The questionnaire was not validated and its intention was to better target the topics to be addressed in the educational videos.

\section{Pharmaceutical Strategies and Interventions}

All patients who signed the consent form were invited to participate in a WhatsApp ${ }^{\circledR}$ group to remind them about taking the medication and pharmaceutical monitoring of these patients. The objective was to ensure the patient-health professional bond, provide pharmaceutical care and increase their adherence to 
treatment. In addition, the availability of telephone contact guaranteed patients access to information without having to travel to the hospital.

The educational videos were developed through the free website Animaker (https://www.animaker.co/) and Powtoon (https://www.powtoon.com/), released for non-commercial product development. The illustrative content was carried out using Canvas.

In this study, three educational videos were developed for the patients, in Portuguese, accessible on Youtubeß:

\section{1) Leprosy: part 1}

https://www.youtube.com/watch?v=cAsRAfABF30\&t=6s

\section{2) Leprosy: part 2}

https://www.youtube.com/watch?v=Ej514KELymo

\section{3) Leprosy: part 3}

https://www.youtube.com/watch?v=UE_H4Q6VylY

\section{Statistical analysis}

For all analyses, a significance level of $p \leq 0.05$ was adopted. The following tests were performed during the construction of this study: McNemar's exact test for paired proportions; Shapiro-Wilks test of numerical variables; Mann-Whitney non-parametric test; $X^{2}$ Test; Generalizer Estimating Equations (GEE) method.

\section{Results}

Until April 2021, there were 98 patients taking their medications at the HCFMRP-USP Ambulatory Pharmacy for the treatment of leprosy. We interviewed 42 patients initially, but only 38 remained until the end of the study. The others decided to leave the study due personal issues. The mean age found was $51.43 \pm 16.15$ years, with a minimum age of 22 years and a maximum of 83 years.

The sociodemographic characterization demonstrated an adult population, declared male (64.3\%), brown (52.4\%), with no or low education (up to elementary school) $(71.5 \%)$, married $(40.5 \%)$, retired $(45.2 \%)$, who do not smoke (85.7\%), do not use alcohol (76.2\%) and do not perform physical activity (66.7\%). Of the patients who reported having other types of diseases, other than leprosy, the prevalence was arterial hypertension (31\%).

When asked about the use of Hansen's disease medications, more than $75 \%$ of patients believe that medications improve their symptoms and that this occurs within 3 months after starting use (58.1\%) (Table 1 - in the ending of the article). 
Regarding the SALSA scale, most patients had mild or no limitation (69.1\%). Regarding the risk awareness score, $31 \%$ of patients did not score, and the second highest percentage $(19 \%)$ was associated with a score of 1 (very low), followed by $14.3 \%$ for 5 points.

Besides, this study wanted to assess the social participation of these patients before and after follow-up, to find out if there was a significant difference between the data, in order to find out if they felt more welcomed and less stigmatized with their diseases (Table 2).

To assess whether there was a statistically significant difference in adherence to treatment after the intervention, McNemar's exact test was performed for paired proportions in the responses obtained in MGT. It was found that there is a significant difference in the results, with the percentage of adherents after the intervention being significantly higher than the percentage of adherents before $(78.4 \%>35.1 \%)$, with $\mathrm{p}<0.001^{*}$.

Unlike the MGT, when patients are asked for a single question, in HST, the percentage of adherents before treatment is already high in comparison with post intervention adherents.

The same McNemar test was performed for HST, in order to assess whether the intervention performed in the research interfered with the patients' adherence results. Regarding before and after, the result was very close to the level of significance $(p=0.07)$, with a tendency towards a significant difference between before and after $(81.1 \%<97.3 \%)$.

However, it is very clear that the HST and MGT tests assessed differently the adherence of the study patients. To assess the association between the HST and MGT, the McNemar test was performed and the Kappa coefficient of agreement was calculated. There is a significant difference $\left(p<0.001^{*}\right)$, the percentage of adherence in MGT before the intervention is significantly lower than that of HST $(37.5 \%<$ 82.5\%) (Table 3).

After calculating the Kappa (0.23) with a confidence interval of $95 \%(0.05-0.40)$, a $p=0.03^{\star}$ was obtained, that is, the coefficient is significantly different from 0 , but your interpretation would only be reasonable.

Assessing the association of the tests after the intervention, there is a significant difference $\left(p=0.04^{\star}\right)$, the percentage of adherents in MGT is significantly lower than that of HST $(76.3 \%<94.7 \%)$. After calculating Kappa (0.11) with a 95\% confidence interval, it was found that the coefficient is not significantly different from $0(p=0.42)$, and its interpretation would be weak.

For the variable gender in association with adherence in MGT, we have $X^{2}=5.18$ and $p=0.02 *$. In other words, there is a significant difference, the percentage of adherents is significantly higher in females $(60.0 \%>24.0 \%)$, with the Odds ratio $=4.75$ and $95 \% \mathrm{Cl}(1.19-18.92)$, it can be inferred that females are 4.7 times more likely to be adherent, before any intervention, which could not be observed in HST (Table 4). 
Other variables did not influence adherence before the intervention. However, the variable mental illness influenced the result of adherence to the HST: with $p<0.001^{*}$, there was a significant difference, with the percentage of adherents being significantly higher in those who did not have mental illness $(96.8 \%>$ $33.3 \%$ ). That is, those who have mental illness are 58 times more likely to be non-adherent (Odds ratio $=$ 58.8), Cl 95\% (5.09-100.1).

In this study, there was no significant difference in the association of the color variable with adherence to MGT and HST before and after the intervention. Therefore, color does not influence treatment adherence. The same was true for the variable marital status and occupation, which did not affect patient adherence before the intervention.

We initially tested the normality (Shapiro-Wilks test) of the age variable for the MGT and HST. We found that only age did not reject the hypothesis of normality, so we applied Student's $t$ test and treatment time for this variable. We applied the non-parametric Mann-Whitney test. There is no significant difference between ages and the results obtained in terms of adherence or not to treatment using MGT and HST.

In HST, it is verified that using the Exact $X^{2}$ test for linear trend, there is a significant linear association ( $p$ $\left.=0.03^{*}\right)$. That is, as education increases, adherence significantly increases, even before the intervention.

To understand the impact of the intervention performed with the patients, a comparison of MGT variable between before $x$ after (Time variable) of the intervention was performed. For this analysis we used the method known as Generalizer Estimating Equations (GEE), which is an extension of generalized linear models that allows the analysis of repeated measures or other correlated observations, in longitudinal studies.

We used the Binary Logistics function for the adjustment. The covariance matrix used was the "unstructured" type. In this way, we were able to assess the predictive factors for adherence, that is, the evolution of adherence. We can see, with the Wald Chi Square value equal to 12.752 , that there is a significant difference $\left(p<0.001^{*}\right)$ between before the intervention and after the intervention in the results of treatment adherence by the MGT: $77 \%>37 \%$.

When we evaluated the gender variable, this significant interaction $(p \leq 0.05)$ indicates that the evolution, the increase, in MGT rate evolved, increased in a significantly different way between the sexes. That is, sex influences the way the adherence rate evolves (graph 1).

The percentage of schooling was not different before ( $31 \%$ vs. $50 \% p=1.00)$ or after $(83 \%$ vs $60 \% p=$ 1.00). However, the educational level of the group of patients who have completed elementary school was $31-83 \%\left(p<0.001^{\star}\right)$ while the other group who had at least high school, even if incomplete, was 50$60 \%(p=1.00)$. We infer that practically all the increase in the rate from $33-77 \%$ is due to the low education group, including a higher final rate in males (83\% vs $60 \%)$. However, it must be emphasized that, before the intervention, the adherence rate of those who had at least high school education been higher than that of the other group. 
When we grouped the variables "no limitation" with "mild limitation" in SALSA scale against the other variables and compared them with the adherence data obtained by HST, we observed an $X^{2}=5.18$ and $p$ $=0.001^{\star}$. Therefore, there is a significant difference and the percentage of adherents is significantly higher in the group without limitation with mild limitation $(96.4 \%>50.0 \%)$. The odds ratio obtained was 27.02, with I.C.95\% (2.72-250). Thus, it can be noted that patients classified as "No limitation" or "mild limitation" are 27 times more likely to adhere to the treatment (Table 4). The same could not be observed in MGT.

As the other test of the research hypothesis was to demonstrate a possible variation in the level obtained by the participation scale, that is, the increase in the perception of oneself, socially, it was evaluated whether there was a relationship between the results obtained in the scale and adherence to the treatment. It was possible to verify that there is a significant difference $\left(p<0.001^{*}\right)$, with the percentage of adherents obtained by the HST being significantly higher in patients classified as "Unrestricted" compared to "Extreme restriction" (100\% > 20\%).

When comparing the data before the intervention and after the intervention for the participation scale, using the McNemar exact test, we noticed that the value of $p=0.07$ is very close to the adopted significance level $(p \leq 0.05)$ indicating a strong tendency to have a significant increase in the percentage of pooled patients who were classified as "no restriction and light restriction" (from 65.8-81.6\%) after the intervention. This indicates a strong tendency to claim that intervention with pharmaceutical care improves patients' social perspective (Table 2).

When we grouped the variables "without restriction" with "slight restriction" against the other variables and compared them with the adherence data obtained by the Haynes test, we observed an $X^{2}=5.18$ and $p=0.02^{*}$. Therefore, there is a significant difference and the percentage of adherents is significantly higher in the group that was classified as "no restriction" and "light restriction" (92.9\% > 58.3\%). The odds ratio obtained was 9.26 , with I.C. $95 \%$ (1.47-48.52). Thus, it can be noted that patients who obtained a classification of "No restriction" or who have "light restriction" are 9.2 times more likely to adhere to the treatment. The same could not be observed in MGT (Table 4).

All data generated or analyzed during this study are included in this article, therefore there is no supplementary material.

\section{Discussion}

The data obtained in this research are very similar to the data from other researcher ${ }^{15}$. Low-income and low-education adult men are common in epidemiological studies on leprosy $16,17,18,19$.

The best way to control leprosy is early diagnosis, which requires strategic guidance from the population regarding signs and symptoms. Thus, educational actions must be intensified for an effective elimination of the disease $\mathrm{e}^{20}$. 
Educational videos are already used as strategies in health education, including technological resources that enhance collaborative practices in health promotion and autonomous learning. The use of animations helps in the patient's understanding, as they can better visualize what health professionals tried to explain previously or even learn something new, and they can be seen and reviewed as often as they like, as well as sharing with other people. Health education is a strategy for the development of patient self-care and learning. It is the development of awareness of your own care to have a healthier life.

According to another group of research ${ }^{21}$, the use of educational videos favors the development of autonomy in taking care of oneself, through a critical reflection of their own context. The use of this technological strategy has been widely used in cancer patients ${ }^{22,23}$.

This study chose to use the SALSA Scale (Screening of Activity Limitation and Safety Awareness), developed based on the International Classification of Functioning Disability in Health (ICF) for application in diabetes mellitus, leprosy or other peripheral neuropathies. The scale assesses the limitation of activities and the risks of increasing disabilities caused by these chronic diseases. Its Portuguese version is already validated and was important in the analysis of how limiting the disease is for the patient under study ${ }^{24}$.

According to studies, multibacillary patients are the ones with the most activity limitations ${ }^{17,25,26}$ and studies have shown that SALSA scale scores tend to increase with age ${ }^{16,27}$.

The results obtained demonstrate that, although the HCFMRP patients are, for the most part, relapsed and multibacillary, they do not have many physical limitations. Only $14.3 \%$ of patients report a very severe limitation. That is, physical dysfunction is frequent in patients with leprosy and, despite being independent in performing daily activities, they have difficulty in instrumental activities ${ }^{28}$.

In this context, the Participation scale has also been validated in Portuguese and it scales the restriction of the patient's social participation, especially for those where the disease is highly stigmatized, interfering in their social activities ${ }^{24}$. Our results show that patients do not feel stigmatized by the disease to the point of affecting their social life.

In this study, $59.5 \%$ of patients had no significant restriction, while $9.5 \%$ had extreme restriction. In the literature, it was possible to find similar data, with a reflection on the results. While one points out that $66 \%$ of volunteers had restrictions on social participation ${ }^{29}$, another points out that most patients

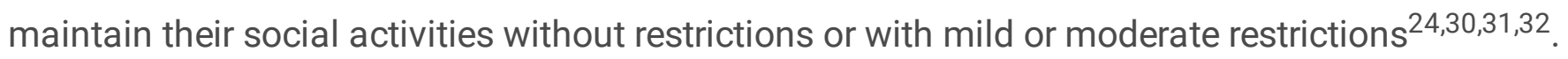

Multibacillary leprosy was predominant in this study. This was probably due to the fact that Hospital das Clínicas is a referral hospital, where patients with difficulty in treating the disease or who have relapsed are transferred. It is noteworthy that a researchers group ${ }^{33}$ presented in their work that the chance of 
noncompliance with multibacillary treatment is double compared to paucibacillary, showing once again the importance of monitoring the adherence of these patients.

When we analyze in detail the answers given before and after the intervention, it is clear that the increase in adherence was mainly due to the patients' not forgetting to take the medication. This was probably due to the sending of messages to the Whatsapp $\AA$ group reminding everyone that they should take their medications, as well as being aware of the carelessness of taking incorrect times.

Regarding treatment adherence, a higher rate of positive answers was found in questions 1 and 2 in MGT, which refer to forgetfulness or carelessness when taking medications. The same was found in studies with hypertensive patients, indicating that forgetfulness and carelessness when taking medications are the greatest difficulties for patients and that it affects their adherence to treatment ${ }^{34}$.

It is therefore concluded that the two tests actually assessed adherence in a very different way. This is probably because the MGT has a much more investigative and detailed character, with up to 6 questions to be answered, while the HST bases the adherence of the study population on just a single question.

In view of the results obtained, it is noteworthy that HST questioning is made in a friendlier way in relation to the MGT, expressing the lowest possible level of pressure. However, this can lead to a low sensitivity in detecting non-adherence, which has already been pointed out among studies with chronic diseases $^{35}$.

In this study, we can point out the absence of a consensus on what would be the ideal treatment adherence assessment method, in addition to the fact that several methods used in the literature make comparison difficult. However, it was possible to estimate the adherence to treatment of a sample of patients being treated for leprosy at the HCFMRP, which contributed to the construction of materials and data that provided and can guide other interventions for this group of patients.

Unfortunately, it was not possible to list the causes of possible non-adherence to treatment, which opens up a range of options for future research in the area to discover and understand the related factors. Furthermore, it is very important to emphasize that there is a need for more studies involving different contexts, since this research was carried out within a specific reality of the health service, with a small sample and hard treatment patients.

\section{Conclusion}

Health education requires ongoing professional training, always seeking excellence in the action it proposes to carry out and improving the quality of life and health of the patient. Such achievements agree with the national health promotion policy and with the guidelines of the SUS. Health education programs help empower patients to be self-sufficient, make decisions about their treatment and be able to identify symptoms and situations that should be analyzed by a health professional. 


\section{Abbreviations}

HST: Haynes-Sackett Test; MGT: Morisky-Green Test; HCFMRP: Hospital das Clínicas da Faculdade de Medicina de Ribeirão Preto; SUS: Sistema Único de Saúde; WHO: World Health Organization; SALSA: Screening of Activity Limitation and Safety Awareness; USP: University of São Paulo, GEE: Generalizer Estimating Equations; PB: Paucibacilar; MB: Multibacilar.

\section{Declarations}

\section{Acknowledgments:}

We wish to acknowledge the HCFMRP/USP and population participants.

\section{Authors' contributions}

AHC: the principle investigator, participate in data collection, data analysis, interpreted the results and wrote the manuscript. MACF: medical review of manuscript. AQU: the main supervisor and contributed in the manuscript design and review. All authors read and approved the fnal manuscript.

\section{Funding}

No funding.

\section{Availability of data and materials}

The datasets generated and/or analysed during the current study are not publicly available due ethics concerns but are available from the corresponding author on reasonable request.

\section{Declarations Ethics approval and consent to participate.}

This study was submitted for analysis by the Research Ethics Committee of the HCFMRP-USP, under protocol 008344/2020 and approved on 05/26/2020, under CAAE $n^{\circ} 28669720.7 .0000 .5440$. Although some volunteers were illiterate, only people of legal age were accepted in this study. An illiterate patient was considered to be one who did not know how to sign his own name, thus requiring a companion to sign the informed consent. I confirm that all methods were performed in accordance with the relevant guidelines and regulations in the country and approved by an ethics committee.

\section{Consent for publication}

Not applicable

\section{Competing interests}

The author(s) declared no potential conficts of interest with respect to the research, authorship, and/or publication of this article. 
Author details

1 Universidade de São Paulo - USP, Brazil. 2 Universidade de São Paulo - USP; Brazil. 3 Universidade de São Paulo - USP, Brazil.

\section{References}

1. -Blevins KE, Crane AE, Lum C, Furuta K, Fox K, Stone AC. Evolutionary history of Mycobacterium leprae in the Pacific Islands. Philosophical Transactions of the Royal Society B. 2020;375(1812).

2. -Souza EA, Heukelbach J, Oliveira MW, Ferreira AF, Sena Neto SA, Raposo MT, et al. Baixo desempenho de indicadores operacionais de controle da hanseníase no estado da Bahia: padrões espaço temporais, 2001-2014. Revista Brasileira de Epidemiologia. 2020;23:e200019

3. -Ministério da Saúde (MS). Secretaria de Vigilância em Saúde. Departamento de Vigilância das Doenças Transmissíveis. Guia prático sobre a hanseníase [recurso eletrônico]. Brasília: Ministério da Saúde, 2017.

4. -World Health Organization (WHO). Number of new leprosy cases: 2019. [updated 2019; cited 2021 Mar 4]. Available from: https://apps.who.int/neglected_diseases/ntddata/leprosy/leprosy.html

5. -Ministério da Saúde (MS). Secretaria de Vigilância em Saúde. Boletim Epidemiológico. Hanseníase - número especial. Brasília: Ministério da Saúde, 2021.

6. -World Health Organization (WHO). Guidelines for the diagnosis, treatment and prevention of leprosy. New Delhi: World Health Organization, Regional Office for South-East Asia; 2017.

7. -Ministério da Saúde (MS). Secretaria de Vigilância em Saúde. Departamento de Vigilância Epidemiológica. Autocuidado em hanseníase: face, mãos e pés. Brasília: Editora do Ministério da Saúde, 2010.

8. -Rocha TPO, Figueiredo Neto J, Fernandes DR, Santana EEC, Abreu JER, Cardoso RLS. Estudo comparativo entre diferentes métodos de adesão ao tratamento em pacientes hipertensos. Int $\mathrm{J}$ Cardiovasc Sci. 2015;28(2):122-9.

9. -Maymone MB, Venkatesh S, Laughter M, Abdat R, Hugh J, Dacso MM, et al. Leprosy: Treatment and management of complications. Journal of the American Academy of Dermatology. 2020;83(1):1730.

10. -STATULATOR. Sample Size Calculator for Comparing Paired Proportions. Disponível em < http://statulator.com/SampleSize/ss2PP.html> Acesso em: Março de 2021

11. -Morisky DE, Green LW, Levine DM. Concurrent and predictive validity of a self-reported measure of medication adherence. Medical care. 1986:67-74.

12. -Haynes RB, Taylor DW, Sackett DL, Gibson ES, Bernholz CD, Mukherjee J. Can simple clinical measurements detect patient noncompliance? Hypertension. 1980;2(6):757-64.

13. -Group SCS, Group SCS. The development of a short questionnaire for screening of activity limitation and safety awareness (SALSA) in clients affected by leprosy or diabetes. Disability and 
Rehabilitation. 2007;29(9):689-700.

14. -Van Brakel WH, Sihombing B, Djarir H, Beise K, Kusumawardhani L, Yulihane R, et al. Disability in people affected by leprosy: the role of impairment, activity, social participation, stigma and discrimination. Global health action. 2012;5(1):18394.

15. -De Sousa AA, de Oliveira FJF, de Jesus Costa ACP, Neto MS, de Oliveira Cavalcante EF, Ferreira AGN. Adesão ao tratamento da hanseníase por pacientes acompanhados em unidades básicas de saúde de Imperatriz-MA. SANARE-Revista de Políticas Públicas. 2013;12(1).

16. -Nogueira PSF, Barbosa RGB, Almeida PCd, Florêncio CMGD, Marques MB, Teles LMR. Aplicabilidade do instrumento "Screening of Activity Limitation and Safety Awareness" em idosos com hanseníasea. Escola Anna Nery. 2020;24.

17. -Loures LF, Mármora CHC. Suporte e participação social em indivíduos com hanseníase. 0 mundo da saúde. 2017;41(2):244-52.

18. -Abraçado MDEFS, da Cunha MHCM, Xavier MB. Adesão ao tratamento de hanseníase em pacientes com episódios reacionais hansênicos em uma unidade de referência. Revista Pan-Amazônica de Saúde. 2015;6(2):23-28.

19. -Lima MAR, Prata MO, Moreira D. Perfil da hanseníase no Distrito Federal no período de 2000 a 2005. Comun ciênc saúde. 2008:163 - 70.

20. -Moreira AJ, Naves JM, Fernandes LFRM, Castro SSd, Walsh IAPd. Ação educativa sobre hanseníase na população usuária das unidades básicas de saúde de Uberaba-MG. Saúde em debate. 2014;38:234-43.

21. -Dalmolin A, Girardon-Perlini NMO, Coppetti LdC, Rossato GC, Gomes JS, Silva MENd. Vídeo educativo como recurso para educação em saúde a pessoas com colostomia e familiares. Revista gaúcha de Enfermagem. 2017;37

22. -Braga F, Garbin L, Marmol M, Khouri V, Vasques C, Carvalho E. Higiene bucal de pacientes em quimioterapia: construção e validação de um vídeo educativo. Revista de enfermagem UFPE on line [Internet]. 2014;8(10):3331-9.

23. -Razera APR, Buetto LS, Lenza NdFB, Sonobe HM. Vídeo educativo: estratégia de ensinoaprendizagem para pacientes em tratamento quimioterápico. Ciência, Cuidado e Saúde. 2014;13(1):173-8.

24. -Barbosa JC, Ramos Jr AN, Alencar MJF, Castro CGJ. Pós-alta em hanseníase no Ceará: limitação da atividade funcional, consciência de risco e participação social. Revista Brasileira de Enfermagem. 2008;61:727-33.

25. -De Castro LE, Da Cunha AJLA, Fontana AP, Halfoun VLRDC, Gomes MK. Physical disability and social participation in patients affected by leprosy after discontinuation of multidrug therapy. Leprosy review. 2014;85(3):208-17.

26. -Ikehara E, Nardi SMT, Ferrigno ISV, Pedro HdSP, Paschoal VDA. Escala Salsa e grau de Incapacidades da Organização Mundial de Saúde: avaliação da limitação de atividades e deficiência na hanseníase. Acta fisiátrica. 2010;17(4):169-74. 
27. -Girardi DR, Bulegon H, Barra CMM. A decision support system based on leprosy scales. International Journal of Biomedical and Biological Engineering. 2010;4(3):70-4.

28. -Amaral LKS, Felippe LA, Gonçalves GH, Christofoletti G. Limitações de tarefa na hanseníase e sua associação com cognição e sintomas neuropsiquiátricos. Revista Brasileira de Enfermagem. $2021 ; 74$.

29. -Barroso Carregosa E, Tais Cunha de Souza V, de Souza Santana L, de Sales SR, Santos Bomfim M, Paixão Amado F, et al. Mapeamento das incapacidades cinésio-funcionais de acordo com a CIF em pessoas diagnosticadas com hanseníase. Fisioterapia Brasil. 2020;21(5).

30. -Monteiro LD, Alencar CH, Barbosa JC, Novaes CCBS, Silva RdCPd, Heukelbach J. Pós-alta de hanseníase: limitação de atividade e participação social em área hiperendêmica do Norte do Brasil. Revista Brasileira de Epidemiologia. 2014;17:91-104.

31. -Brandão Bezerra P, Carolina de Lima Silva M, do Carmo Ferreira de Andrade M, Vasconcelos Carvalho da Silva L. Avaliação física e funcional de pacientes com hanseníase. Journal of Nursing UFPE/Revista de Enfermagem UFPE. 2015;9(8).

32. -Reis B, Castro S, Fernandes L. Limitação da atividade e restrição da participação social em relação à faixa etária, ao sexo e à escolaridade de pessoas com hanseníase. An Bras Dermatol [Internet]. 2017;92(3):339-43.

33. -Ignotti E, Andrade VLGd, Sabroza PC, Araújo AJGd. Estudo da adesão ao tratamento da hanseníase no município de Duque de Caxias-Rio de Janeiro:" abandonos ou abandonados". 2001.

34. -Plaster W. Adesão ao tratamento da hipertensão arterial por idosos usuários da unidade básica de saúde Princesa Isabel em Cacoal-RO. 2006.

35. -Prado J, Kupek E, Mion D. Validity of four indirect methods to measure adherence in primary care hypertensives. Journal of human hypertension. 2007;21(7):579-84.

\section{Tables}

Table 1 to 4 is available in the Supplemental Files section.

\section{Figures}




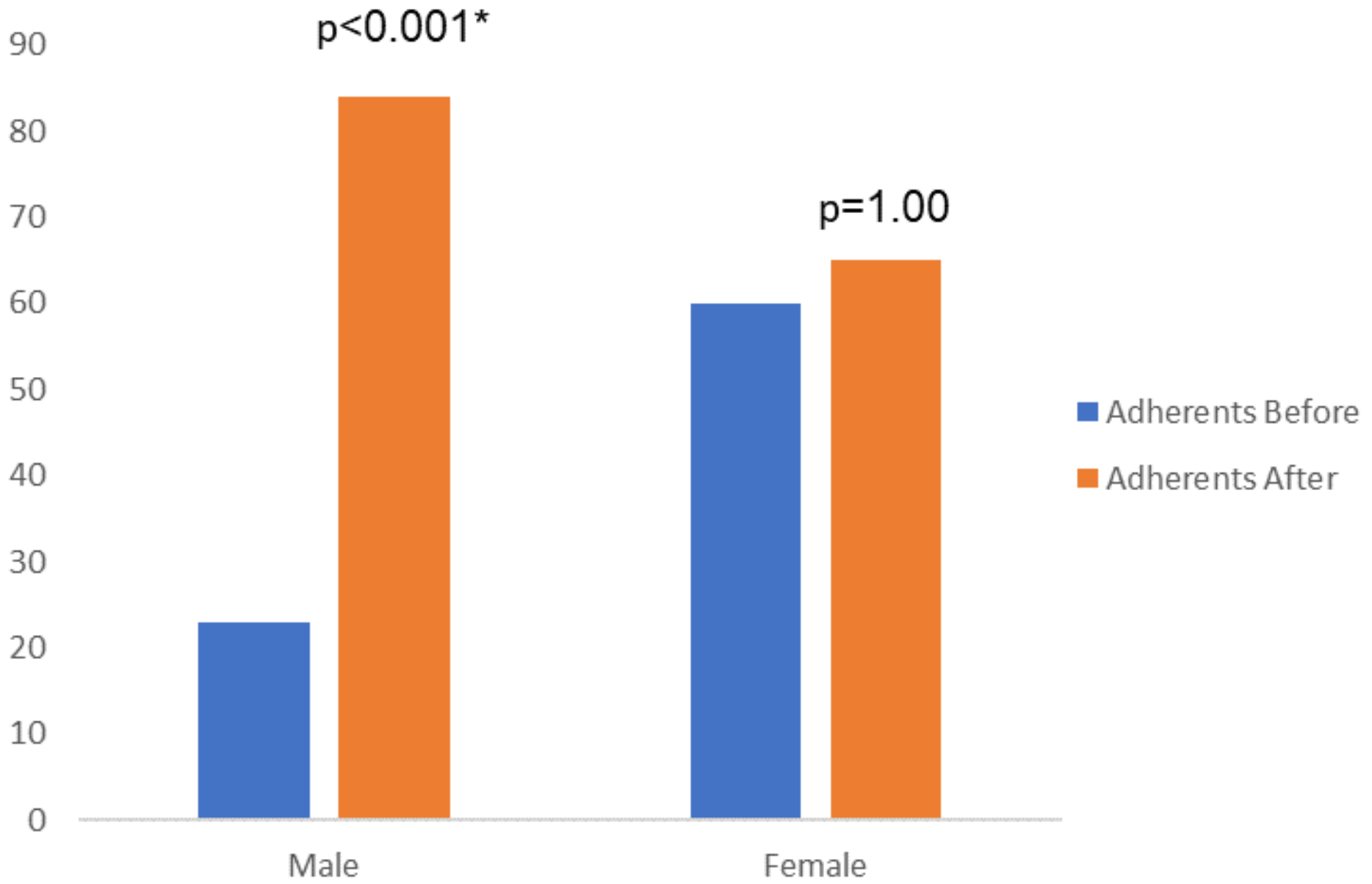

Figure 1

Analysis of the variable sex $x$ adherence (MGT) before and after the pharmacotherapeutic intervention.

\section{Supplementary Files}

This is a list of supplementary files associated with this preprint. Click to download.

- Onlinefloatimage5.png

- Onlinefloatimage1.png

- Onlinefloatimage2.png

- Onlinefloatimage3.png 